\title{
Lectura crítica de McCausland, Elisa (2017). Wonder Woman. El feminismo como superpoder. Madrid: Errata Naturae
}

\author{
Mariela Acevedo \\ Universidad de Buenos Aires, Argentina \\ acevedo.mariela7@gmail.com
}

En Wonder Woman. El feminismo como superpoder, Elisa McCausland -periodista y especialista en cultura popular y feminismo- presenta un recorrido por la historia de la superheroína de los cómics desde sus inicios en 1941 hasta la actualidad. Se trata de un ensayo que analiza en su conjunto la emergencia del personaje femenino de aventuras en el contexto de la Segunda Guerra Mundial, sus transformaciones y las vinculaciones que pueden plantearse con otros productos de la cultura mediática actual. A partir de la trayectoria de Wonder Woman asistimos tanto al momento de expansión del mercado de revistas al calor de la emergencia del hiperconsumismo como a los vínculos que la icónica superheroína teje con el movimiento de liberación de mujeres y las demandas feministas de Estados Unidos. La historia de Wonder Woman es también una historia de Estados Unidos contada desde las reflexiones de una súper mujer que viene a cumplir su misión en "el mundo de los hombres".

\section{Arquetipo, ÍCONO, MARCA}

El ensayo de McCausland se inscribe en un campo de estudios de historieta en español tal como lo define Michel Matly (2017) que dialoga con otras publicaciones, principalmente con los estudios sobre superhéroes desde coordenadas sociológicas, pero también con los estudios que desde los feminismos abordan la representación de las relaciones de género y las lecturas queer de los productos de la cultura popular. En torno a los estudios sobre la superheroína, encuentra asidero principalmente con el trabajo de la historiadora Jill Lepore (2014) a quien además entrevista. McCausland aborda la trayectoria de este personaje clásico vinculado al feminismo y a la cultura popular en su veta mainstream o comercial desde múltiples entradas a partir de las cuales nos invita a un ejercicio de pensamiento sobre las dimensiones del arquetipo mítico, el ícono feminista y la marca comercial que representa Wonder Woman.

El amor por la creación marstoniana es declarado por McCausland desde sus propósitos iniciales: "Uno de los objetivos de este libro es recorrer los cómics de la superheroína para comprobar qué guionistas, decisiones editoriales y épocas han sabido honrar o revisar con argumentos de calidad, y cuáles no, las nociones de Marston" (McCausland, 2017, pp. 36-37). Se refiere a las nociones desplegadas por un "feminismo amazónico" ligado a las luchas sufragistas primero y a la liberación sexual después que se encuentran germinales en la concepción emancipatoria de Diana de Themyscira, la amazona de Isla Paraíso, ilustrada para la ocasión por Natacha Bustos y Carla Berrocal. Entre los registros de ambas artistas, se sintetiza esa combinación de clásica y (pos)moderna presente en la superheroína.

A través de una minuciosa reconstrucción bibliográfica, McCausland recupera las intervenciones públicas del psicólogo e investigador William M. Marston quien entendía el cómic como medio expresivo y valoraba 
positivamente su potencial educativo. Marston, a quien Mcausland define como "un anfibio cultural" tenía claro que era necesario "un personaje heroico femenino" que equilibrara la "aplastante presencia de personajes masculinos”. En 1941 estas ideas fueron plasmadas en la primera aventura dibujada por Harry G. Peter, en palabras de Marston "una indisimulada propaganda psicológica para el nuevo tipo de mujer que debería, en mi opinión, dominar el mundo.”

\section{Pluralidad metodológica}

El exhaustivo abordaje de McCausland recorre y analiza las distintas dimensiones del personaje, el sentido de sus aventuras en distintas etapas y su vinculación con el contexto norteamericano y mundial a la largo de más de siete décadas. La revisión bibliográfica es notable y se inserta en la reconstrucción de un campo de historieta feminista que se delinea no solo en la búsqueda de visibilidad de las autoras, sino también en las propuestas gráficas que elaboradas por autores y autoras han podido ser atractivas para pensar el lugar de la lectora. Una lectora que se construye históricamente como apunta Nattie Golubov (2011) para la los estudios literarios.

La autora reescribe así una historia del cómic desde la crítica feminista en la que entreteje sus propias reflexiones e indagaciones con las voces de artistas que intervinieron en la creación de la Wonder Woman que conocemos hoy. De modo que además de reponer la historia de la amazona, los vaivenes económicos de $D C$ Comics y su competidora Marvel, la transposición de las historietas a los medios audiovisuales y los diferentes contextos de producción y recepción de las aventuras, la periodista entrevista a lo largo del libro a distintas personas que operan en la construcción poliédrica y polisémica del personaje. Además de la entrevista a la historiadora Lepore con quien reconstruye los orígenes del mito; McCausland dialoga con Joanne Edgar, editora de la revista feminista $M s .{ }^{1}$ y con la historietista y herstorian del medio Trina Robbins, una de las primeras autoras en participar en la creación de aventuras de la amazona. También aportan su punto de vista historietistas involucradxs en distintas sagas de la superheroína como Phil Jiménez, Greg Rucka, Gail Simone y Renae De Liz.

A través de nueve capítulos, un prólogo y un epílogo la investigadora madrileña propone un recorrido que parte de la propuesta del "Clan Marston" y llega hasta la previa al estreno de la película Wonder Woman, de Patty Jenkins (2017), primer film dedicado completamente al personaje.

En los dos primeros capítulos, McCausland se apoya en Lepore (2014) para reconstruir los lazos afectivos del psicólogo William Moulton Marston con Elizabeth Holloway y Olive Byrne, cocreadoras que no firman la obra pero cuya intervención resulta clave para la creación de la amazona. La vinculación que ambas tuvieron con las luchas y demandas feministas de su tiempo se plasma en el ideario de Wonder Woman aunque solo lleven la firma de Marston. Tras su muerte en 1947 se cerrará un ciclo para la Wonder Woman de la etapa conocida como golden age e inicia la deriva del personaje que McCausland reconstruye apelando a un arsenal de datos y papers que permiten configurar vaivenes, declives y renacimientos del personaje.

\section{Historia de un Signo: LO QUeER y LO FEMinista en Wonder Woman}

En el tercer capítulo la autora aborda las dos décadas posteriores a la muerte de Marston donde el entorno amazónico de sororidad y connotaciones sáficas presentes desde el origen pierden peso frente a una $W o n d e r$ Woman familiera y sentimentaloide. Este sendero, ajeno al sentido primigenio lleva a que en 1961 la cabecera de la amazona sea elegida como "el peor cómic del año". La domesticación progresiva en las viñetas se corresponde con lo que la autora entiende como rasgos de "irrealidad de la vida en Estados Unidos de posguerra”. Así, portadas y tramas le permiten a la investigadora abordar la cultura norteamericana a través de los cómics y contextualizar la regresión de la superheroína en la Era de Plata. McCausland acuerda en entender la década de los '50 como la "más nociva para los derechos y libertades y la menos humorística de los 
Estados Unidos", pero también como el momento en el que germina una cultura del disentimiento descrita en el libro-hito La mistica de la feminidad de Betty Friedan (1963). Es además el momento en el que se forja un escenario contracultural subterráneo que resiste a los embates conservadores. Entre ellos, el más importante para los cómics es el que tiene como protagonista la obra del psicólogo alemán Frederic Whertam y su célebre La seducción de los inocentes (1954) que tendrá un impacto relevante al condensarse su denuncia de los comics en el Comics Code o código de autocensura que rigió hasta 2011.

En este apartado, y en referencia al juicio que el psicólogo expresó en torno a la lesbiandad de la superheroína, McCausland sostiene que "Wertham tuvo razón en todo lo que señaló, ya que era muy consciente del poder del medio en que se había gestado el personaje: en los cómics más inspirados de Wonder Woman -l os creados por el clan Marston, pero, también, los de George Pérez o Greg Rucka- lo queer, los j uegos de poder y sumisión y su filosofía implícita, el discurso a favor de la emancipación de la mujer han permeado viñetas cuya imaginación desbordante se debatía con los límites de la censura, la comprensión lectora, hasta hacer sutilmente de la mente del lector y la lectora un espacio más libre y consciente de cuanto le rodeaba" (McCausland, 2017, p. 89). Lo que Wertham temía con justa razón señala McCausland- es el i mpacto que implicaba que una lectura menospreciada hasta por sus propios editores y accesible a niñas y niños pusiera en labios de una mujer reflexiones sobre el mundo sexista y excluyente que hemos creado.

En el siguiente capítulo McCausland describe las transformaciones que suceden en el género superheroico a fines de los años '60, la Era de Bronce del personaje. Es el momento donde Wonder Woman se consolida como ícono feminista y donde se reconoce su potencia como marca comercial. El lanzamiento de $M s$. con la superheroína en la portada ${ }^{\circ} 1$ en el verano de 1972 inaugura lo que McCausland llamará "feminismo pop". El rescate del superheroína remite a la creación original de Marston y se repetirá como estrategia en los aniversarios $30^{\circ}, 35^{\circ}$ y $40^{\circ}$ (portadas de $M s$. en 1997, 2007 y 2012, respectivamente) en lo que la investigadora califica como un reciclaje de imágenes del pasado para convocar a nuevas generaciones de feministas. Wonder Woman le permite a McCausland reponer los debates que se dieron al interior del movimiento de mujeres enfrentando sus vertientes liberales y radicales: Ms. con Wonder Woman en portada se anuda a las estrategias del sector liberal del movimiento que busca discutir una enmienda de igualdad entre varones y mujeres (Equal Rights Admiend-ERA) introducida al debate por primera vez en 1923. Con la idea de explicar la enmienda igualitaria, $M s$. instaló en la agenda pública el cuestionamiento a la violencia contra las mujeres y el acoso sexual naturalizados como prácticas habituales. La enmienda no logró ser debatida en ese entonces y cayó en el olvido hasta que recientemente se reactivó como demanda con la llegada al poder en 2017 de Donald Trump. McCausland logra así hacer visible los hilos que unen la historia, la cultura masiva, las demandas políticas y los consumos culturales, de manera que no parece casual que frente a la política antifeminista del actual presidente de Estados Unidos se hayan generado distintas respuestas gráficas entre las que volvemos a encontrar a Wonder Woman: la amazona reaparece en representaciones públicas que reclaman justicia y equidad.

\section{Relatos transhumantes}

McCausland no limita su análisis a las historietas de DC Comics sino que en los siguientes capítulos seguirá los pasos de la amazona por otros medios y relatos: construirá puentes entre Wonder Woman y su influencia en otras ficciones, entre la que destaca la intertextualidad que mantiene con la Promethea de Alan Moore (1999-2005) que coincide con una observación de Trina Robbins: "Promethea es todo lo que debería haber continuado siendo Wonder Woman desde la marcha de Marston” (McCausland, 2017, p. 173). En esta línea y con Donna Haraway como referente, McCausland lee una sugerente transición de superheroina a tecno-heroina y de diosa a cyborg que pervive renovada en nuevos relatos.

La investigadora extiende además su abordaje a las intervenciones de los grandes estudios de Hollywood que explotan los personajes de DC Comics y -su competidora en el género superheroico, Marvel- por lo que 
dedicará espacio a las propuestas audiovisuales entre las que se encuentra la exitosa teleserie protagonizada por Lynda Carter en los años '70 pero también a proyectos recientes que no llegaron a estrenarse en público. Además, la autora indagará sobre la reapropiación del ícono realizado desde el espacio underground que reacciona frente a la censura del Comic code. Tal como reconstruye Elena Masarah (2016) el comix aunque disruptivo frente a la corriente principal "políticamente correcta" resultaba tan sexista como el comic mainstream lo que empujó a muchas autoras de historieta identificadas con el movimiento de liberación de las mujeres a crear espacios sororales en una sisterhood historietil. Desde la portada de la ya clásica primera publicación conjunta de autoras de historieta It ain't me Babe! (1970) germen de Wimmen Comix (revista de historieta feminista que se publicó entre 1972-1992) a las publicaciones más cercanas a fanzines como Tits \& clits o Abortion Eve, la figura de la amazona apareció para plasmar las luchas del feminismo. Así en el fanzine Sister de 1973 Wonder Woman aparece -espéculo en mano- para poner en agenda el derecho al aborto.

\section{CHica Posmo}

La historia que reconstruye McCausland señala que en febrero de 1986 con el número 329 concluye oficialmente la primera etapa histórica de Wonder Woman tras cuarenta y cuatro años de publicación. Al filo de los '90, la amazona se encontrará frente a un nuevo escenario: el que encuentra en el coleccionismo de ediciones originales y números especiales un fetiche que atesorar. Lo clásico adquiere un brillo especial que refuerza el valor de marca comercial de la amazona. Surgen las convenciones y los espacios que homenajean a los personajes, y el público, aunque no lea cómics acumula sus figuritas: el merchandising y el cosplay acompañan los estrenos en las pantallas. Los personajes de cómics se transforman en piezas fundamentales en la legitimación de marcas que operan en el mundillo de los videojuegos, la imagen digital, Internet y las plataformas comerciales. Aun así, la investigadora muestra cómo se bifurca la marca de su protagonista de aventuras en papel al señalar que Wonder Woman tuvo su peor década entre 1991 y 2001, período en el que no figuró ni una vez entre los cien cómics más vendidos. El nuevo milenio y el escenario bélico impulsarán representaciones de Diana que volverán a vincularla -como en sus inicios- a lo patriótico: la superheroína adopta el cuerpo de la mujer-soldado y acompaña a las tropas que parten a la Guerra del Golfo. También el $11 \mathrm{~S}$ tendrá implicancias para todo el universo superheroico que se ve sacudido con el atentado contra las Torres Gemelas.

Escribe McCausland: "El mito bebe de esencias de orígenes que han apuntalado sistemas de poder, que han escrito sobre el cuerpo, sobre la página en blanco realidades. El arquetipo superheroico es heredero de esos sistemas de poder, cuyos orígenes están vinculados a la historia y sus reescrituras; en la actualidad, al sistema de mercado que lo sostiene y al heteropatriarcado que lo impulsa y lo vigoriza. Las hazañas del superhéroe se conciben como el camino campbelliano que seguir, siempre en masculino genérico. La superheroína, heredera de sufragistas, amazonas y feministas de segunda ola, ¿puede aspirar a un camino propio?" (McCausland, 2017, pp. 152-153).

Ese camino accidentado que nos invita a recorrer McCausland junto a la superheroína nos lleva a preguntarnos por nuestro propio camino. Tal como recuerda Trina Robbins, Marston ideó un argumento donde Wonder Woman postulaba a la presidencia en el año 3000, "parecía pensar que tendrían que pasar mil años antes de que una mujer sea presidenta de nuestro país”, reflexiona la historietista.

El ensayo de McCausland discute simplificaciones instaladas que entienden el género superheroico como un género entretenido y compensatorio. Refuta la concepción de que "el cómic como fábula no puede hacer justicia a lo histórico y las narraciones clásicas o que el espectáculo no puede albergar aristas críticas que remuevan al lector" (McCausland, 2017, p. 200). Por el contrario, el análisis que propone la investigadora destaca el potencial de la cultura popular para pasar por debajo del radar de lo establecido y desde allí apuntar a los sistemas de poder. Wonder Woman puede entenderse entonces como mito perdurable que toma distintas formas, pero que cobra pleno sentido cuando entendemos que "el superpoder siempre ha sido el feminismo". 
La historia que teje McCausland es fascinante, invita a la lectura y reflexión; y aunque hubiéramos agradecido que incluyera imágenes de las portadas y páginas de historieta, sus descripciones y una rápida búsqueda en internet completan lo que resulta ser un fascinante viaje ficcional por la historia reciente.

\section{ReFERENCIAS}

Golubov, N. (2011). La teoría literaria feminista y sus lectoras nómadas. Revista discurso, teoría y análisis, 31, 37-61. Lepore, J. (2014). The secret history of Wonder Woman. New York: Knopf.

Masarah Revuelta, E. (2016). Lecturas feministas en el cómic autobiográfico contemporáneo. Filanderas. Revista interdisciplinar de estudios feministas, 1,77-88.

Matly, M. (2017). El estado de la ciencia. investigación y cómic. Revista Tebeosfera. Tercera Época, 2. Recuperdo de ht tps://www.tebeosfera.com/documentos/el_estado_de_la_ciencia._investigacion_y_comic.html

\section{Notas}

1 La revista $M s$. (en español: Señora ) es una revista feminista y liberal de Estados Unidos fundada por las activistas Gloria Steinem, Dorothy Pitman Hughes quienes intervienen en la construcción icónica de Wonder Woman para el feminismo en $\operatorname{los}$ '70.

2 McCausland sigue la división habitual que separa la historia de los cómics de superhéroes en "eras" o "edades" donde la Era dorada o Golden Age corresponde con la emergencia Superman en 1938, Batman en 1939 y Flash en 1940. 